\title{
PRIMARY RESEARCH \\ The effects of inlet airflow angle on the quality of mixing air distribution in an aircraft cabin mock-up
}

\author{
Mahmoud Mohamed Attalla ${ }^{1}$, Mohamed Abdelfadiel Mohamed ${ }^{2 *}$, Sabry Mohamed Iraqi ${ }^{3}$
}

\author{
1, 2 South Valley University, Qena, Egypt \\ ${ }^{3}$ Luxor International Airport, Luxor, Egypt
}

\begin{abstract}
Index Terms
Aircraft Cabin

CFD Simulation

Mixing Air Distribution System

Inlet Airflow Angle

Received: 15 March 2017

Accepted: 21 July 2017

Published: 21 August 2017

Abstract - This paper presents a numerical investigation on the effects of inlet airflow angle on the airflow, temperature and $\mathrm{CO}_{2}$ concentration fields in a three-row airliner cabin. The computations are conducted using Ansys-Fluent and the numerical results were compared against published experimental data. The inlet airflow is supplied into the aircraft cabin at six different directions of $\mathrm{A}\left(0^{\circ}, 180^{\circ}\right), \mathrm{B}\left(355^{\circ}\right.$, $\left.185^{\circ}\right), \mathrm{C}\left(350^{\circ}, 190^{\circ}\right), \mathrm{D}\left(340^{\circ}, 200^{\circ}\right), \mathrm{E}\left(330^{\circ}, 210^{\circ}\right)$ and $\mathrm{F}\left(315^{\circ}, 225^{\circ}\right)$. The numerical results showed that flow pattern, temperature distributions and $\mathrm{CO}_{2}$ levels are improved significantly inside the whole cabin and at passengers' breathing zones in case of changing the inlet airflow angle. The performance of mixing-air distribution system for the whole aircraft cabin is enhanced remarkably in case of using small inlet angles. Angles $\mathrm{B}\left(5^{\circ}\right)$ and $\mathrm{C}\left(10^{\circ}\right)$ provided the best ventilation performance among the six tested angles within the whole cabin and at local breath zones of passengers in terms of thermal and health comfort. Moreover, inlet airflow angle $\mathrm{C}\left(10^{\circ}\right)$ showed high constancy and stability in the pattern of the flow field and temperature and low $\mathrm{CO}_{2}$ level in cabin centre area compared to inlet airflow angle $\mathrm{B}\left(5^{\circ}\right)$ for both the whole aircraft cabin and local breathing zones.
\end{abstract}

\section{INTRODUCTION}

Modern commercial aircrafts must cruise at high altitudes to achieve the best performance and it is essential to keep a comfort and healthy cabin conditions from the air distribution system. At these high altitudes, the air properties are completely different from the one at standard conditions, hence much process have to be done on this air to be suitable for passengers environment [1]. Currently, the aircraft engine compressor is the main source of ventilation system fresh air, which should be manipulated well before the supplying into the cabin. This fresh air has a vital role in controlling the air quality within the cabin environment. However, this method may increase the amount of fresh air, but with penalty of reducing the en- gine performance and the consequent increase in fuel consumption due to low thrust. Airline companies are aspiring to reduce the amount of outside fresh air into the passengers' cabin to conserve fuel, consequently adversely affecting the air quality [2]. These challenges stimulated the researchers and scientists to put many suggestions for improving the air quality inside the commercial aircraft cabins, while reducing the fuel consumption. A detailed review of the available air quality data for aircraft passenger cabins in the period from 1977 to 1997 was published by Hocking [3] to provide useful information for researchers. The review collected crucial data from the viewpoint of both the passengers and airlines, hence, proposals for improving the air quality were concluded. Accordingly, a Computational Fluid Dynamics (CFD) model was applied to inves-

\footnotetext{
* Corresponding author: Mohamed Abdelfadiel Mohamed

†Email: moha_attalla@yahoo.com
} 
tigate the air quality inside a Boeing 767 aircraft cabin during cruise conditions. The model provided a simulation data for three different ventilation systems, mixing, under-floor displacement and personalized system in terms of velocity, temperature and $\mathrm{CO}_{2}$ contamination fields $[4,5]$. The results showed that, although the personalized ventilation system might decrease the risk of spreading the airborne particles, it could increase the level of temperature dissatisfaction among passengers. Moreover, the mixing ventilation system had more uniform velocity, temperature and $\mathrm{CO}_{2}$ contaminations within the whole cabin than the other two systems, but it had the highest $\mathrm{CO}_{2}$ level in the breathing zone. Mixing ventilation system is currently implemented in commercial aircraft cabins to provide uniform air and temperature distributions. Although it provides a satisfactory environment within the commercial aircraft cabin, it could spread infamous particles. Since, this ventilation system is already applied in today's aircraft, it is important to improve its design performance for that objective. An experimental work was conducted to characterize the airflow pattern, ventilation effectiveness and pollutant transport within a Boeing 767 cabin section has five rows [6, 7, 8]. Volumetric Particle Tracking Velocimetry (VPTV) technique was used to measure the three-dimensional air velocity profile within this cabin mock-up. The local mean age of air and Ventilation Effectiveness Factor (VEF) were measured at five levels of air supply rates and two levels of heating load. The results showed that the local mean age of air was inversely proportional to the air supply rate, while the VEF remained consistent. Moreover, the exposure risk was considerably reduced when the distance between the airborne source and the receptors was increased $[7,9]$. Because infectious particles can spread within an aircraft cabin from a sick passenger, an experimental measurements and CFD simulations were conducted to quantify the airflow and contaminant transmission in a full-scale Boeing 767 - 300 aircraft cabin [10] and in a section of half occupied, twin-aisle cabin mock-up [11], respectively. The airflow patterns provided from the CFD model were validated with those measured experimentally. Both studies demonstrated that the CFD results could help researchers more accurately to identify the mechanism of pollutant transport and provide important information for the areas which is difficult to get from experiments. In light of that, a detailed CFD study was conducted using Reynolds-Averaged NavierStokes (RANS) and Large Eddy Simulations (LES) methods to investigate the air flow distributions and airborne pathogen dispersion in a small section of Boeing 767-300 passenger aircraft cabin $[12,13,14]$. It was shown that, the RANS simulation results under-predicted the value of turbulent intensity at the breathing zone, however the LES results were more realistic compared to the available experimental data. On the other hand, the effect of a moving human body on the comfort and health environment in an aircraft cabin is studied using experimental and CFD techniques [14]. Particle Image Velocimetry (PIV) and Planar Laser-Induced Fluorescence (PLIF) measurements showed that the movement of the human body affected adversely on the ventilation effectiveness and these results were used to validate the implemented CFD model. Numerical simulations were carried out to evaluate the effectiveness of applying periodic air supply method at constant flow rate for ventilating the cabin of a Boeing 767-300 passenger aircraft $[15,16]$. The results showed that the air quality inside the cabin is improved due to the mixing between fresh and expired air compared to using the conventional steady air supply. Since the passengers' aircraft cabin has a complex geometry, small volume and lower percentage of fresh air per person compared to general buildings, it is essential to pay more attention to design an effective air distribution system. Numerous experimental and numerical studies are conducted to investigate the efficiency of different air distribution systems inside passenger aircraft cabin. Based on the above review, most researchers studied the effect of some parameters such as cabin geometry, the positions of the inlet and outlet air, the airflow rate and the heat load inside the cabin.

The present study addresses the effect of inlet airflow angle on the ventilation effectiveness of the mixing air distribution system inside passenger aircraft cabins. The study is performed numerically using three-dimensional version of Ansys-Fluent software. The review showed that, although the mixing air distribution system creates a uniform air and temperature distribution, but it possibility spreads the airborne particles. To improve the existing air distribution system inside the aircraft cabins, six inlet airflow angles are evaluated in terms of flow, temperature and contamination fields. Therefore, a comprehensive assessment of varied inlet airflow angles on the air quality inside a Boing 767 aircraft cabin mock-up is obtained. The structure of the present paper is as follows; first, the governing equations, commercial aircraft cabin section and grid generation are presented. The boundary conditions applied in the present CFD model, inlet airflow angles configuration and solution algorithms are introduced next. Thereafter, the numerical results are presented and discussed before 
conclusions are provided.

\section{NUMERICAL METHODS}

\section{A. Governing Equations}

Three-Dimensional version of commercial AnsysFluent software is used in the present study. To consider the unsteadiness behaviour on the airflow inside the cabin, a steady-state flow field was selected as initial condition subsidiary flow transition. RANS equations are discretised and solved to obtain flow, temperature and species transport parameters. The RNG $\kappa-\varepsilon$ turbulence model is applied to simulate the generation and dissipation of turbulent energy because it has much performance and robustness in modelling the indoor flows among other turbulence models $[17,18]$. The flow inside the aircraft cabin is assumed incompressible, steady and three-dimensional. For Newtonian, incompressible fluid, the conservation form of the flow governing equations are as follows [1]:

$\nabla \cdot \bar{V}=0$

$\rho \frac{D \bar{T}}{D t}=\nabla \rho+\rho(T) \cdot g+\nabla \cdot\left(\tau-\tau_{T}\right)$

$\rho C_{p} \frac{D \bar{T}}{D t}=\nabla \cdot\left(q-q_{T}\right)$

The species transport equation is employed during the solution to model the $\mathrm{CO}_{2}$ transport inside the aircraft cabin. The renormalization group $(R N G k-\varepsilon)$ turbulence model $[19,20]$ is chosen to predict the airflow, temperature and $\mathrm{CO}_{2}$ infections particles. Moreover, it has been used successfully to simulate the airflow and pollutant transport in numerous internal flow applications [2].

\section{B. Physical Model and Computational Domain}

A typical Boeing 767-300 cabin section is chosen as the physical model of the current simulation, since experimental measurements for the air, temperature and $\mathrm{CO}_{2}$ level are available from the literature for the same domain The domain dimensions were $4.6 \mathrm{~m} \mathrm{(x)}, 2.1 \mathrm{~m} \mathrm{(y)}$ and 2.9 $\mathrm{m}(\mathrm{z})$, which are the same as used in the experiments [11]. The boundaries of air inlet and exhaust outlet are represented with linear slots. Simple geometries are created inside the computational domain to represent the passengers. Structured hexahedral elements are generated for the whole computational domain to calculate the flow, temperature and $\mathrm{CO}_{2}$ contaminant fields. The computational domain is selected as a cabin section enclosing three rows and the customers sat on the seven seats on each row. Three different grids with mesh elements of 518257, 1002855 and 1,480,228 hexahedral elements were used during our study as mesh independent test. The grid with number of mesh elements of 1002855 is used for all the results presented in this paper. The mesh is generated with minimum orthogonal quality of 0.82 and maximum aspect ratio of 2.15. Figures 1 (a) \& (b) show the cabin physical model and 3-D structured mesh generated within the computational domain, respectively.

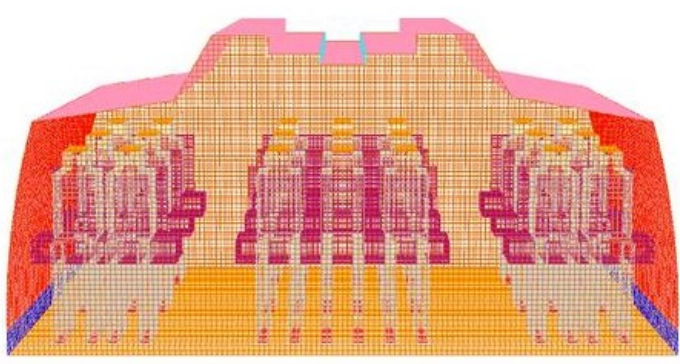

(a)

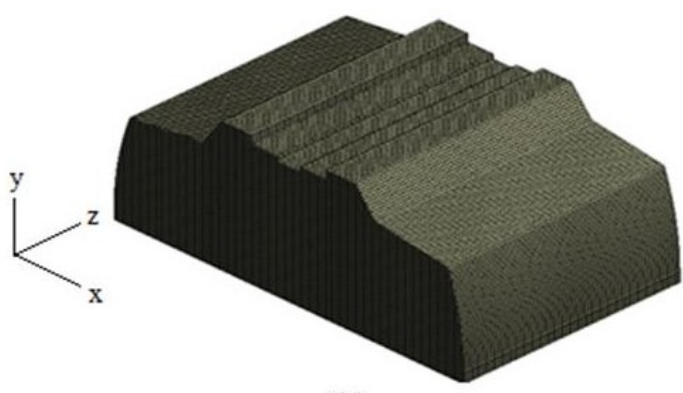

(b)

Fig. 1. Physical model (a) and structure grid (b) of Boeing 767-300 passenger aircraft cabin

\section{Boundary Conditions and Model Sep-Up}

The figures of mass flow rate and temperature of air at inlet supply are kept constant for all modelled cases during the numerical simulations performed in this study. Table 1 shows the types of applied boundary conditions and values of variables used in the present numerical simulations. 
TABLE 1

BOUNDARY CONDITIONS FOR THE PRESENT CFD STUDY

\begin{tabular}{lll}
\hline \hline Item & Type of $\mathrm{BC}$ & $\mathrm{BC}$ variables \\
\hline Fresh air supply & Velocity inlet & $21^{\circ} \mathrm{C} ; 0.085 \% \mathrm{CO}_{2} ; 8.3 \mathrm{~L} / \mathrm{s}$ per passenger (steady supply) \\
Ceiling & No-slip & $24^{\circ} \mathrm{C}$ \\
Side wall & No-slip & $20^{\circ} \mathrm{C}$ \\
Floor & No-slip & $23^{\circ} \mathrm{C}$ \\
Seats & No-slip & Adiabatic \\
Passenger surface & No-slip & $30^{\circ} \mathrm{C}$ \\
Passenger mouth & Velocity inlet & $35^{\circ} \mathrm{C} ; 100 \% \mathrm{CO}_{2} ; 0.005 \mathrm{~L} / \mathrm{s}$ per passenger \\
Air outlet & Outflow & \\
Front and rear of cabin & Periodic & \\
\hline \hline
\end{tabular}

The setting variables are chosen to be consistent with the previous numerical studies $[5,15]$. To model the heat transfer with the surrounding air, constant temperature option selected in the numerical model. The conditions of steady air supply and the $\mathrm{CO}_{2}$ rate from passengers are selected at values that is recommended by Boeing company $[21,22,23,24]$. In the present study, the fresh inlet airflow enters the aircraft cabin through six different angles. Supply diffuser blades will force the inlet air to follow one of the indicated configurations in Figure 2. The six studied configurations are $\mathrm{A}, \mathrm{B}, \mathrm{C}, \mathrm{D}, \mathrm{E}$ and $\mathrm{F}$ that correspond to inlet airflow angles of $\left(0^{\circ}, 180^{\circ}\right),\left(355^{\circ}, 185^{\circ}\right),\left(350^{\circ}, 190^{\circ}\right),\left(340^{\circ}\right.$, $\left.200^{\circ}\right),\left(330^{\circ}, 210^{\circ}\right),\left(315^{\circ}, 225^{\circ}\right)$ respectively.

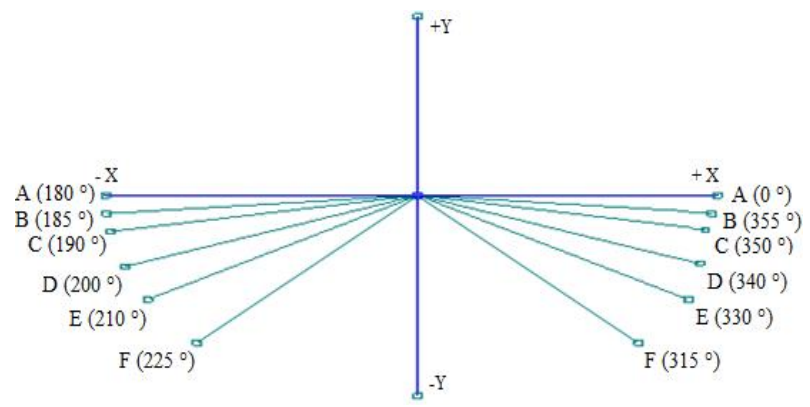

Fig. 2 . Fresh inlet airflow directions, A $\left(0^{\circ}\right), \mathrm{B}\left(5^{\circ}\right), \mathrm{C}\left(10^{\circ}\right), \mathrm{D}$

$\left(20^{\circ}\right), \mathrm{E}\left(30^{\circ}\right) \& \mathrm{~F}\left(45^{\circ}\right)$

The flow governing equations and species transport equation are discretised and solved at the centroid of each cell in the 3D computational domain. Semi Implicit Method for Pressure Linked Equations (SIMPLE) algorithm is selected to couple pressure and velocity. Pressure-Implicit with Splitting of Operators (PISO) scheme is applied for pressure and velocity coupling, which utilizes the splitting of operations in the solution of the discretized momentum and pressure equations. Second-order upwind scheme is selected to discretize the other physical quantities during the simulation.

\section{RESULTS AND DISCUSSION}

\section{A. Validation of a CFD Model}

In the present study, RANS equations are applied to simulate the mixing air system of a passenger's aircraft cabin at different inlet air conditions. It was essential to validate the CFD model first against the experimental data to ensure that consistent and accurate results have been obtained. The cabin flow field under transient inlet airflow is first obtained and compared to the averaged flow pattern provided from experiments [9]. In experiments, VPTV method is used for measuring the air distribution in a B767-300 cabin and vector plots for 24 cross-sectional planes spaced with $0.1 \mathrm{~m}$ are used to calculate the mean value. Figure 3 shows comparison of the velocity vectors coloured by velocity magnitude between the experiments (a) and the present numerical simulations (b) of a plane at the cabin mid-row.

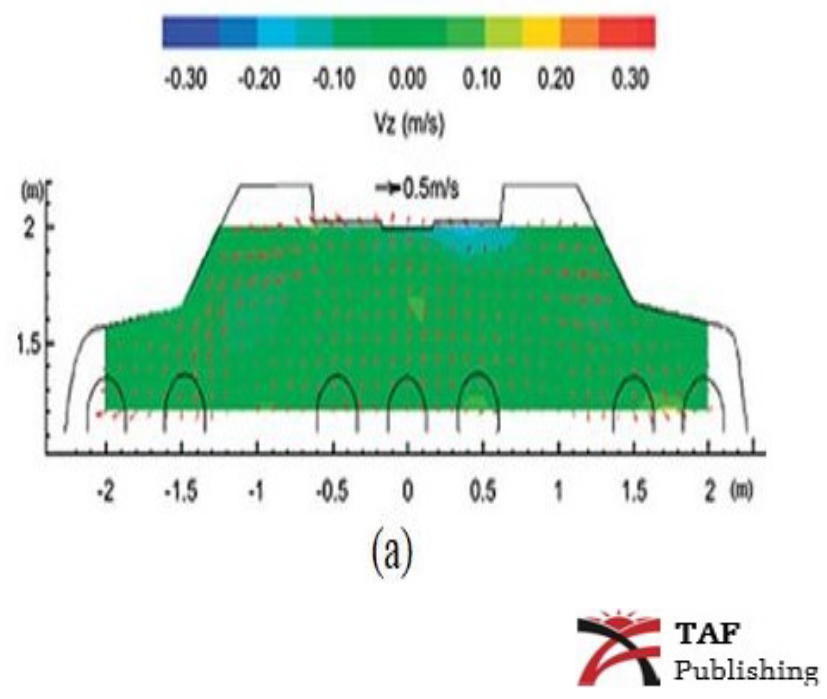




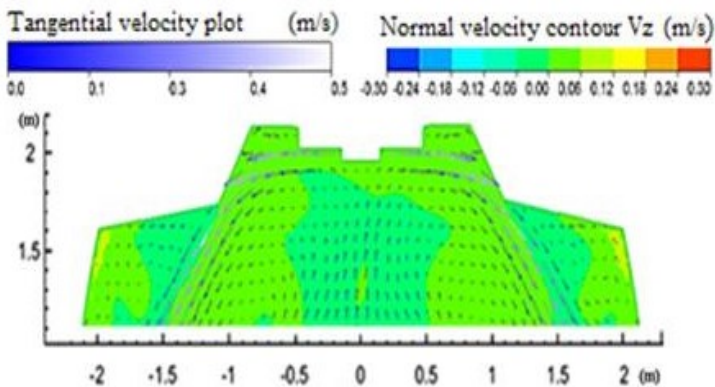

(b)

Fig. 3. Velocity vectors plots coloured by velocity magnitude of plane located at mid-row inside aircraft cabin, (a)experiments [9] (b)- present simulations

Since the simulated airflow is unsteady, thus the instantaneous snapshot of the flow field is not descriptive of the mean flow pattern. Therefore, the simulated velocity vectors illustrated in Figure 3-b represent the average of a number of instantaneous vector plots. From the comparison, it is plain to see that the present CFD simulations are predicted correctly the main features of the cabin airflow illustrated in Figure 3 (a) that include the fresh air path, flow circulations and the streams at the cabin central area. In addition to the mean flow pattern, the validation includes comparison between the measured and simulated local velocity profiles (horizontal and vertical) along the cabin horizontal line, which located in the passengers' breathing zone at $1.4 \mathrm{~m}$ above the cabin ground as shown in Figures 4 (a) \& (b) respectively.

These values also represent the averages of several instantaneous velocity profiles. As demonstrated from Figures 4 (a) and (b), the numerical results for velocity profiles follow the same pathway of the experiential profiles; however it is smaller in magnitude than those in the experiments. This is because the CFD model did not precisely capture the flow structures at the points with small values. However, these quantitative results showed that the present CFD model succeeded to predict the actual pathway of both horizontal and vertical velocity profiles compared to the experimental results.

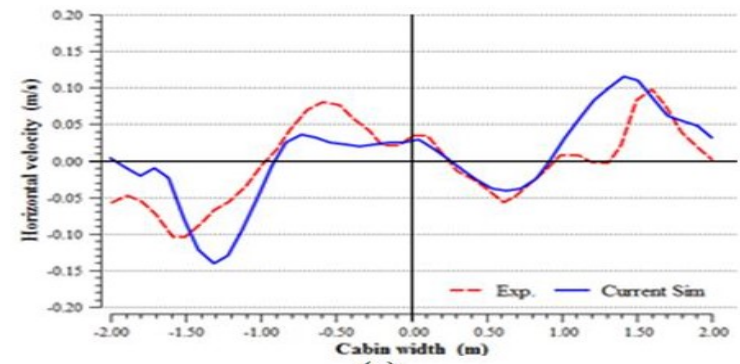

(a)

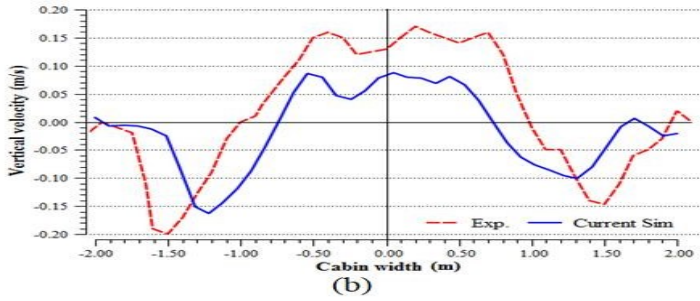

Fig. 4. Horizontal (a) and vertical (b) local velocity profiles at 1.4 $\mathrm{m}$ above the cabin floor

\section{B. Ventilation Effectiveness within the Aircraft Cabin}

Airflow pattern: The numerical results of airflow pattern inside the cabin aircraft are illustrated in Figures 5 (a), (b), (c), (d), (e) and (f). The Figures show the velocity vectors coloured by velocity magnitude of the airflow inside the aircraft cabin for the six inlet air supply directions of A, B, C, D, E \& F respectively. As is evident from the Figures, the fresh air into the cabin through louvers is steady in the areas close to the cabin boundaries where the two passenger side seats are located. The air then becomes unsteady away from the side seats areas and two big eddies appear close to the cabin centreline and then move upwards. The two big eddies move towards the cabin ceiling then it pushed down into the centre or passed through the seats to achieve circulations and finally pull out the cabin from the exhaust outlet port. Figures 5 (a), (b) and (c) show that the pattern of air distribution inside the cabin for directions $\mathrm{A}, \mathrm{B}$, and $\mathrm{C}$ with smaller inlet angle is approximately similar, however the case with direction $\mathrm{C}$ shows the best behaviour among them. This creates high velocity gradient near the cabin sides, hence performing a good mixing air distributions in the cabin and proper ventilation for both passengers and crew. On the contrary, the air distribution inside the cabin for directions $\mathrm{D}, \mathrm{E}$, and $\mathrm{F}$ with bigger inlet angles create high velocity gradient near the cabin centre, hence the fresh air does not stay enough time within the cabin and exits from cabin outlet prior contacting the passengers. Furthermore, several swirls can be seen around the side and centre seats, which results in an unbalanced behaviour of the air distribution inside the aircraft cabin. Therefore, the fresh air supply with bigger inlet airflow angles resulted in poor mixing air distribution inside the cabin and high level of $\mathrm{CO}_{2}$ contaminants. When the airflow reaches the cabin floor, part of this air is withdrawn overboard through the pressurized outflow port and the other part rises up and mixes with the fresh air supply. When the mixing process occurs, the fresh air will exchange heat and momentum with the adjacent air, hence dilutes the $\mathrm{CO}_{2}$ contaminants produced from travellers. 


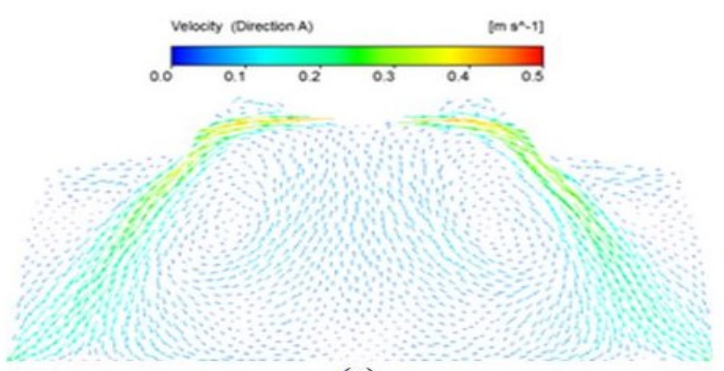

(a)

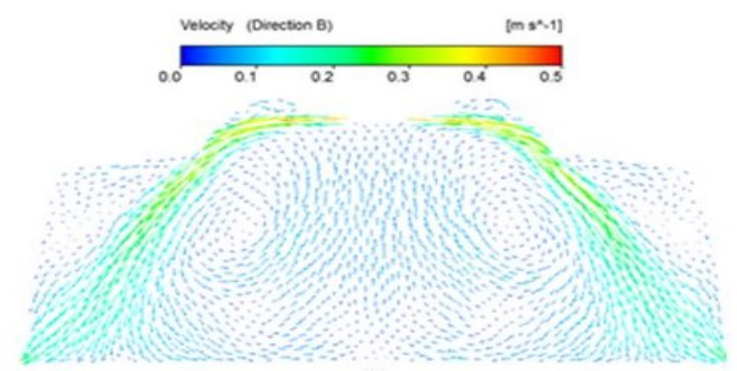

(b)

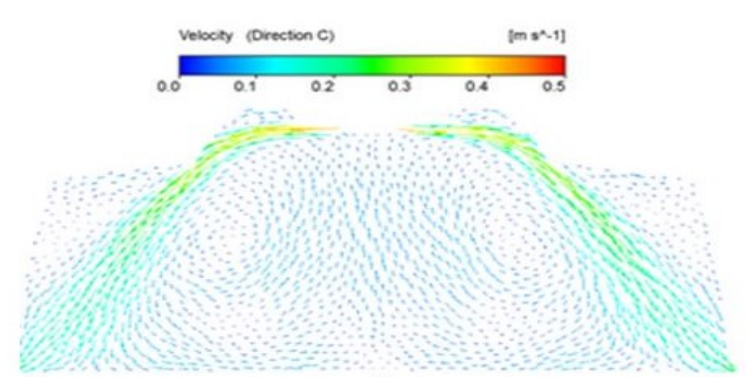

(c)

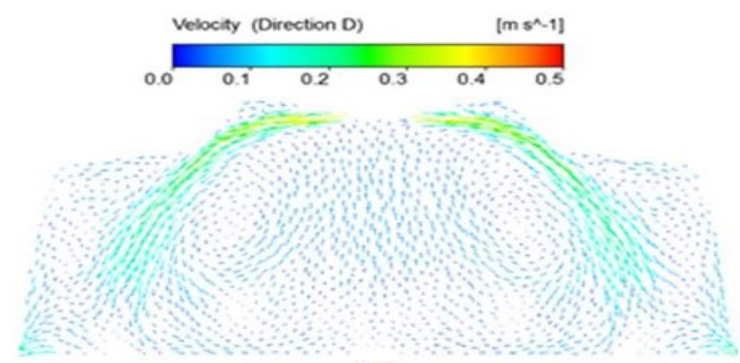

(d)

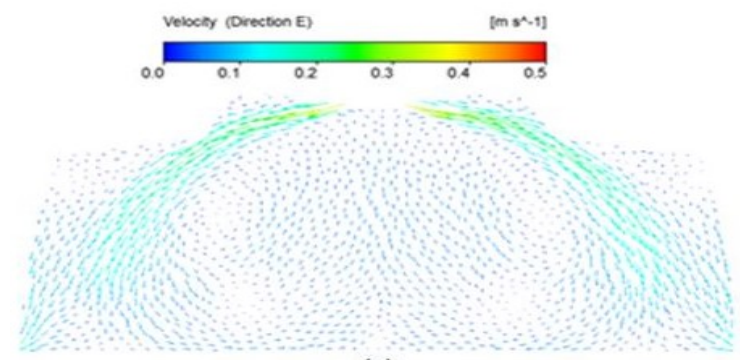

(e)

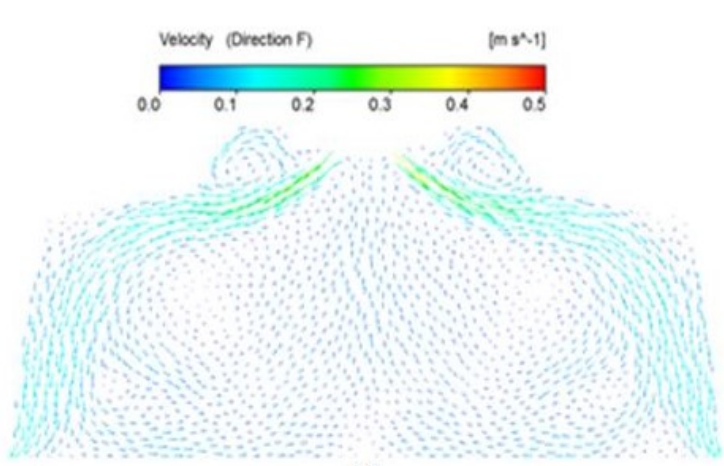

(f)

Fig. 5 . Velocity vectors of the air distribution inside aircraft cabin for different air inlet supply directions; (a)- $0^{\circ}$, (b)$5^{\circ},(\mathrm{c})-10^{\circ},(\mathrm{d})-20^{\circ},(\mathrm{e})-30^{\circ} \&$ (f)- $45^{\circ}$

Temperature field: The temperature distribution of the ventilated air inside the aircraft cabin usually reflects the cooling efficiency and considered as one of the significant factors of thermal comfort for passengers and crew. Figures 6 (a), (b), (c), (d), (e) and (f) show the temperature contours of air inside the aircraft cabin for the six inlet airflow angles of A, B, C, D, E \& F respectively. The plots show that the temperature contours inside the cabin is affected by proper distribution of air volume flow rates. As has been pointed out the overall variance in temperature levels for the first three directions A, B \& C is quite small, while the other three angles have higher level of air temperature. The regions close to the cabin side seats have appropriate air temperature ( $\leq$ $296 \mathrm{~K}$ ), while the regions close the passengers' breathing zones have the highest air temperature $(\leq 302 \mathrm{~K})$. The air temperature is small at the areas of cabin aisles as similar to the areas of side seats. Moreover, the proper air temperature distributions is created in the inlet airflow with A, B and $\mathrm{C}$ orientations. The air temperature of case with direction $\mathrm{C}\left(10^{\circ}\right)$ tends to provide more uniform air temperature through the whole cabin, while the temperature of air farther close to the cabin walls becomes slightly smaller.

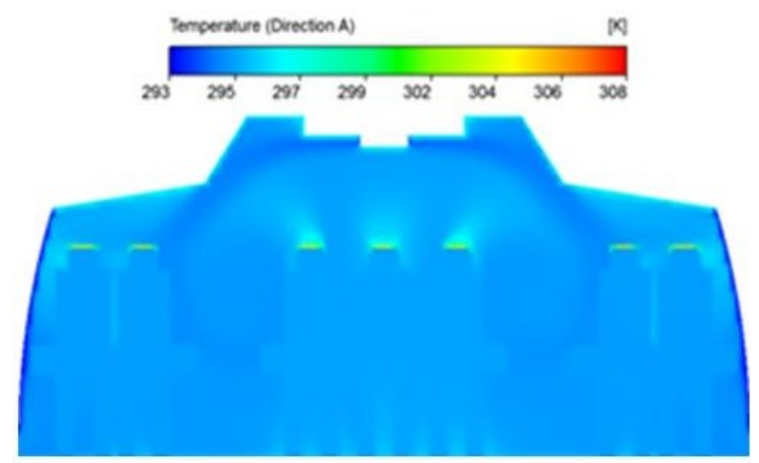

(a) 


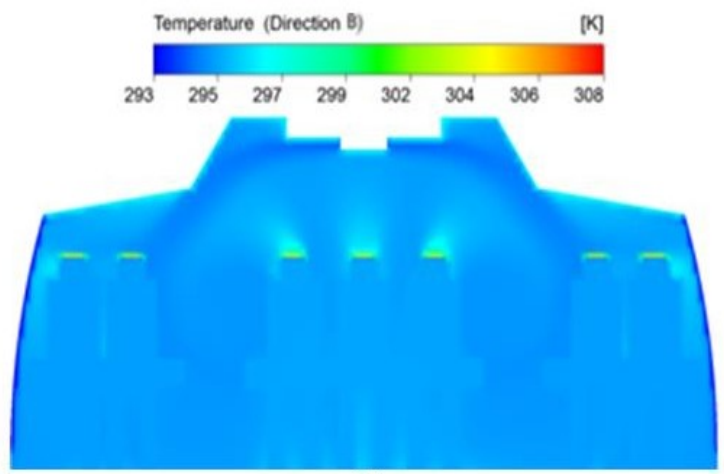

(b)

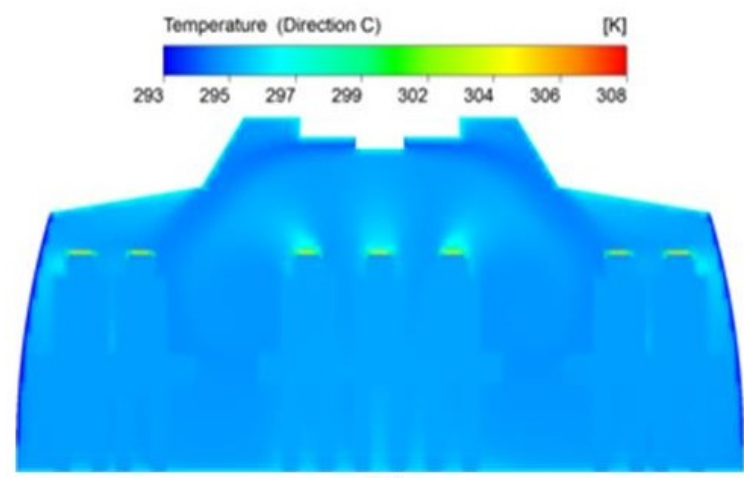

(c)

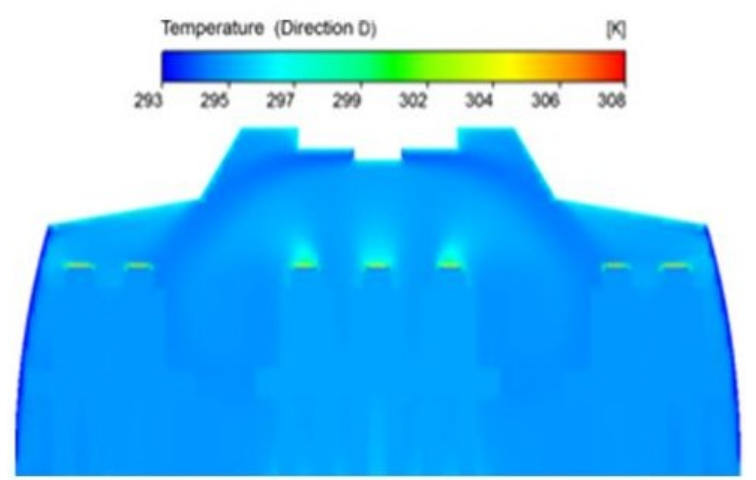

(d)

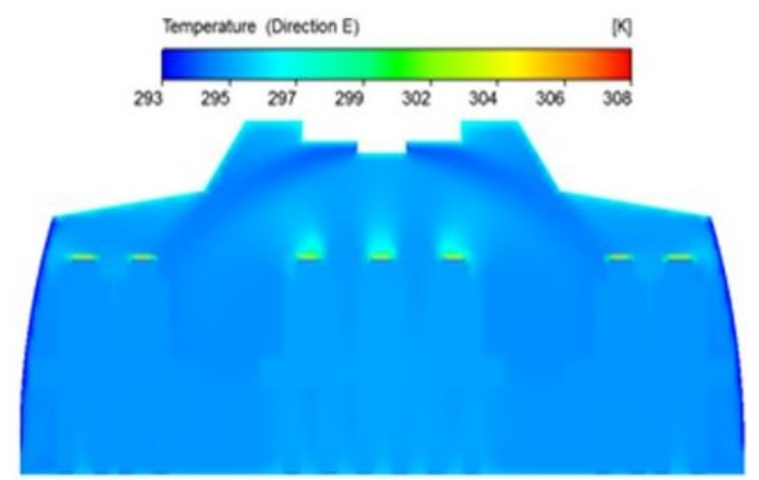

(e)

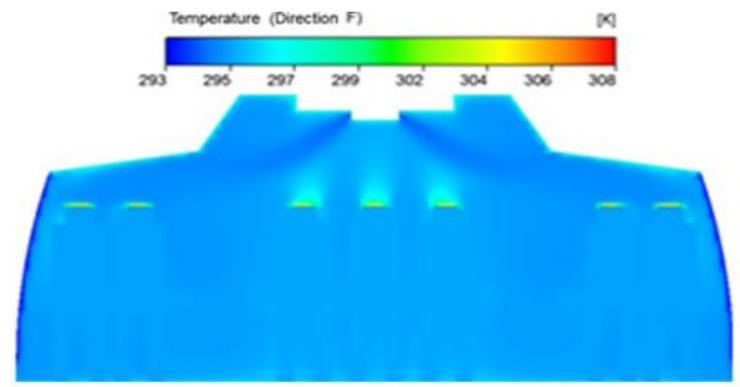

(f)

Fig. 6 . Temperature contours of the air distribution inside aircraft cabin for different air inlet supply directions; (a)$0^{\circ},(\mathrm{b})-5^{\circ},(\mathrm{c})-10^{\circ},(\mathrm{d})-20^{\circ},(\mathrm{e})-30^{\circ} \&$ (f)- $45^{\circ}$

$\mathrm{CO}_{2}$ contamination level: The heath comfort inside the aircraft cabin is quite different from the indoor environments, such as homes and offices, in many aspects such as the small volume, the restrictions on the passengers preventing them from moving freely and the need for pressurization. During flight, passengers face many health and environmental barriers such as low air pressure, low humidity and the possibility of inhaling air contaminated with ozone $\left(\mathrm{O}_{3}\right)$, carbon dioxide $\left(\mathrm{CO}_{2}\right)$ or infectious droplets. In the present study, $\mathrm{CO}_{2}$ concentration level in the aircraft cabin for the six inlet airflow angles is selected as an indication of health environmental comfort. Figure 7 (a) \& (b) show the $\mathrm{CO}_{2}$ concentration of a plane located at mid-row inside aircraft cabin at the inlet angles (first four angles) and at then for optimum three angles that provide minimum $\mathrm{CO}_{2}$ concentration, respectively. Evidently the $\mathrm{CO}_{2}$ concentration increases with increasing the inlet airflow angle and this is shown clearly from Figure 7 (a) and how $\mathrm{CO}_{2}$ level increases (angles $\mathrm{E}$ and $\mathrm{F}$ are not included due to high level of $\mathrm{CO}_{2}$ concentration). On the other hand, small inlet airflow angles provide low $\mathrm{CO}_{2}$ concentration within the whole cabin. Figure 7 (b) shows that inlet airflow angles $\mathrm{B}\left(10^{\circ}\right)$ and $\mathrm{C}\left(20^{\circ}\right)$ provides the minimum $\mathrm{CO}_{2}$ level within the whole aircraft cabin with slightly distribution differences from the centre to the cabin side seats.

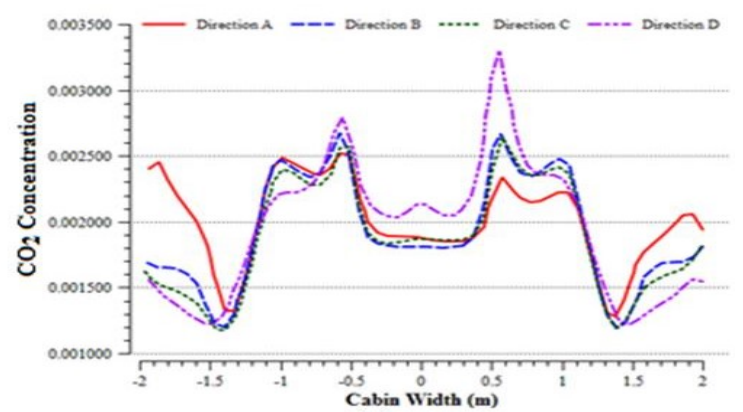

(a) 


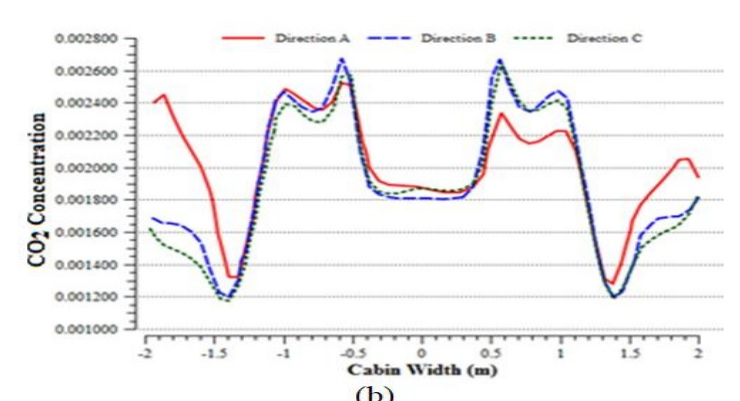

Fig. 7. $\mathrm{CO}_{2}$ concentration level inside aircraft cabin; (a)- Inlet airflow angles of $0^{\circ}, 5^{\circ}, 10^{\circ}$ and $20^{\circ}$, (b)- Inlet airflow angles of $0^{\circ}, 5^{\circ}$, and $10^{\circ}$

\section{Ventilation Effectiveness at Passengers' Breathing Zone}

As discussed is the previous section, the cabin comfort and health environment with mixing air distribution system has small inlet airflow angles is sensibly improved. Angles B $\left(5^{\circ}\right)$ and $\mathrm{C}\left(10^{\circ}\right)$ provided the best air and temperature distributions and lowest level of $\mathrm{CO}_{2}$ concentration within the whole aircraft cabin among the six studied inlet airflow angles. Since, the passengers' breathing level is usually the critical zone within the whole cabin; hence, more analysis has been carried out at this region. As shown in Figure 8, the breathing zone is selected at level of $1.4 \mathrm{~m}$ above the cabin floor and passengers who sit in the midrow of cabin centre plane are the target. The symbols used in the Figure refer to the location and order of passengers' breathing zones within the aircraft cabin. Each symbol consists of two numbers and the letter (P); the first number is (2), which refers to the second row in the cabin section, letter $(\mathrm{P})$ refers to the passenger and the second number takes values from 1 to 7 , which refers to the order of the passenger in the mid-row from left to right. For example, $2 \mathrm{P} 3$ refers to the breathing zone of passenger $(\mathrm{P})$ which is sitting in the mid-row (2) and his order in the mid-row is the third (3) from the left side.

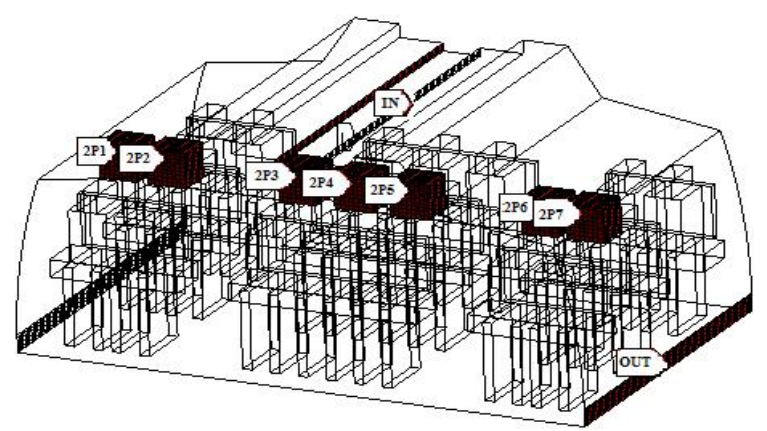

Fig. 8. Breathing zones of passengers 1 to 7 at the cabin mid-row and $1.4 \mathrm{~m}$ above the cabin floor
Figures 9 (a) and (b) show the contours of temperature distributions for passengers' breathing zones who are located at the cabin mid-row and $1.4 \mathrm{~m}$ above the cabin floor level for inlet flow angles B $\left(5^{\circ}\right)$ and C $\left(10^{\circ}\right)$, respectively. The Figures show that the air temperature distributions resulted from directions $B$ and $C$ are quite similar and the temperature difference at the breathing zones for all passengers is within $1 \mathrm{~K}$.

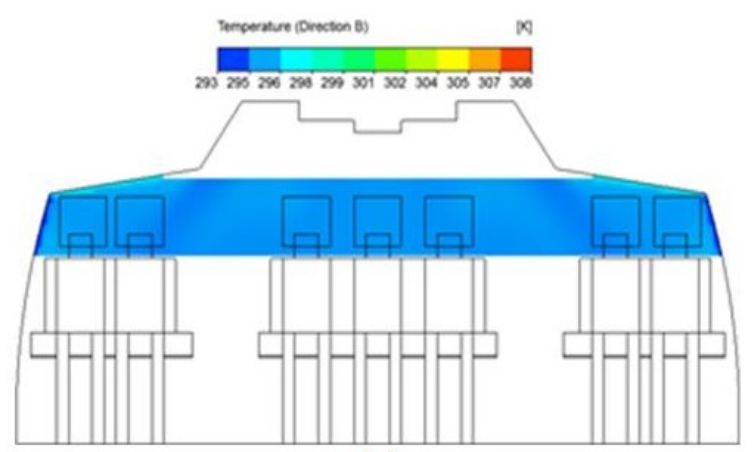

(a)

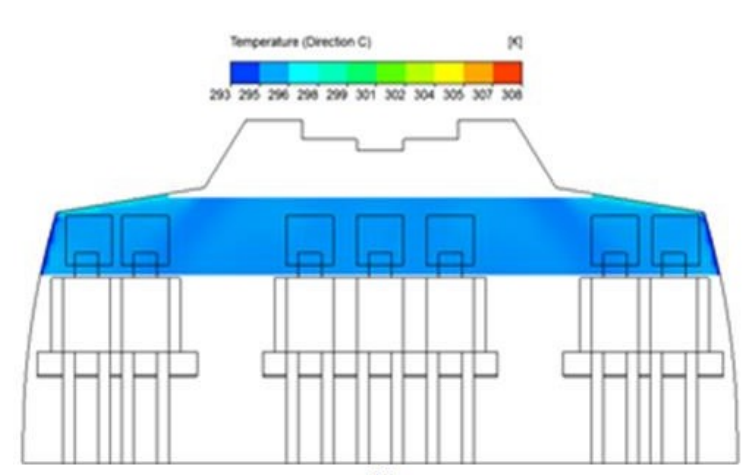

(b)

Fig. 9. Temperature contours for passengers' breathing zones (2P1 : 2P7) at the cabin mid-row and level $1.4 \mathrm{~m},(\mathrm{a})-$ direction $\mathrm{B}\left(5^{\circ}\right)$, (b)- direction $\mathrm{C}\left(10^{\circ}\right.$.)

Similarly, Figures 10 (a) and (b) show the contours of $\mathrm{CO}_{2}$ concentration level for passengers' breathing zones at cabin mid-row and $1.4 \mathrm{~m}$ above the cabin floor level for inlet airflow angles of $B\left(5^{\circ}\right)$ and $C\left(10^{\circ}\right)$, respectively. Thus, directions $\mathrm{B}$ and $\mathrm{C}$ also provide the minimum level of $\mathrm{CO}_{2}$ contaminants at the breathing zones for all passengers, 2P1 - 2P7 and the concentration level at the cabin side seats is less than the cabin mid area. However, the $\mathrm{CO}_{2}$ contamination level is quite higher at certain points close to the passengers 2P1 and 2P7 due to poor circulation in these far regions. Passengers 2P2 and 2P6 have the lowest $\mathrm{CO}_{2}$ contamination level compared to the passengers in the same cabin mid-row. In the other hand, passengers sitting in the cabin centre $(2 \mathrm{P} 3,2 \mathrm{P} 4 \& 2 \mathrm{P} 5)$ are facing the highest con- 
tamination level of $\mathrm{CO}_{2}$. This is can be attributed to that the breathing zones of those passengers lie in the core of the airflow eddies, hence the circulating air spends much time until it's diluted with the fresh air compared to the passengers sit faraway from cabin centre. The concentration level improved slightly with inlet airflow angle $\mathrm{C}\left(10^{\circ}\right)$ compared to angle $B\left(5^{\circ}\right)$, specially for the cabin centre region as shown in Figure 10 (b).

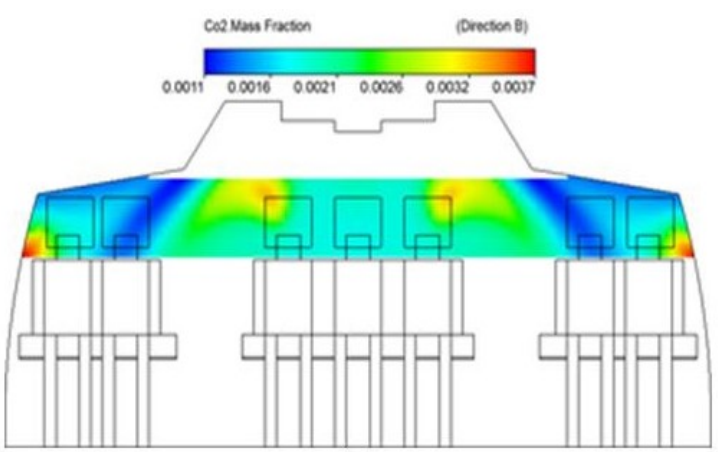

(a)

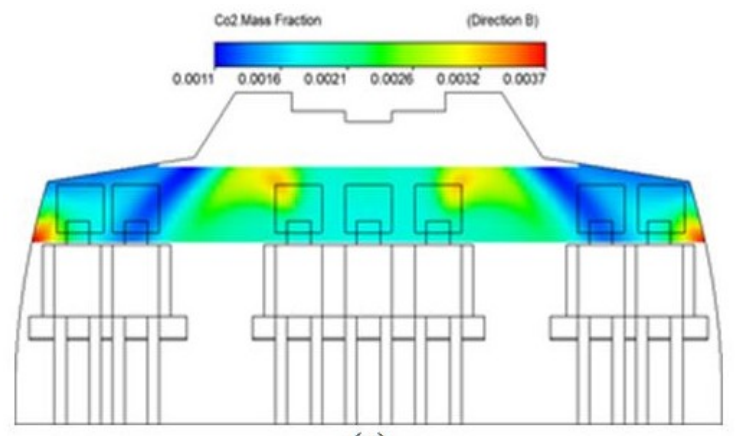

(a)

Fig. 10 . Contours of $\mathrm{CO}_{2}$ concentration for passengers' breathing zones $(2 \mathrm{P} 1: 2 \mathrm{P} 7)$ at the cabin mid-row and level $1.4 \mathrm{~m},(\mathrm{a})$ - direction $\mathrm{B}\left(5^{\circ}\right)$, (b)- direction C $\left(10^{\circ}.\right)$

\section{CONCLUSION}

The effects of changing the inlet airflow angle on the airflow, temperature and $\mathrm{CO}_{2}$ concentration fields inside three-rows cabin section of B767-300 commercial aircraft is investigated numerically using Ansys-Fluent. Six inlet airflow directions of A $\left(0^{\circ}\right), \mathrm{B}\left(5^{\circ}\right), \mathrm{C}\left(10^{\circ}\right), \mathrm{D}\left(20^{\circ}\right)$, E $\left(30^{\circ}\right)$ $\& \mathrm{~F}\left(45^{\circ}\right)$ are studied in the present paper. The numerical results were validated and compared against the published experimental measurements. The quality of air inside the aircraft cabin for each angle is evaluated and analysed inside the whole cabin and at passengers' breathing zones. The numerical results showed that the quality of mixing air, temperature distribution and $\mathrm{CO}_{2}$ contaminant level inside the cabin affected dramatically by changing the inlet airflow angle of the mixing air system. Small air inlet angles provided much better air quality within the whole aircraft cabin and passengers' breathing zones compared to high inlet angles. Directions B $\left(5^{\circ}\right)$ and $\mathrm{C}\left(10^{\circ}\right)$ created the best airflow temperature and $\mathrm{CO}_{2}$ fields within the whole cabin that reflected on the thermal and health comfort for both passengers and crew. In contrary, directions $\mathrm{A}\left(0^{\circ}\right), \mathrm{D}\left(20^{\circ}\right)$, $\mathrm{E}\left(30^{\circ}\right)$ and $\mathrm{F}\left(45^{\circ}\right)$ provided poor air and temperature fields and high $\mathrm{CO}_{2}$ contaminant level within the whole cabin. This can be attributed to the existence of strong and large swirls that generate in case of high inlet airflow angles, hence improper air distribution, high temperature and high $\mathrm{CO}_{2}$ levels inside the whole aircraft cabin. Passengers' breathing zones were isolated and studied individually to find the appropriate inlet airflow angle among the investigated six cases. The results indicated that, directions $\mathrm{B}\left(5^{\circ}\right)$ and $\mathrm{C}\left(10^{\circ}\right)$ also presented the best characteristics of airflow, temperature and $\mathrm{CO}_{2}$ level. However, both angles produced minimum $\mathrm{CO}_{2}$ levels at the cabin side seats, direction $\mathrm{C}\left(10^{\circ}\right)$ showed better results of $\mathrm{CO}_{2}$ levels at cabin midrow compared to direction $\mathrm{B}\left(5^{\circ}\right)$. The results reported in this research could provide meaningful guidelines towards studying more approaches to improve the mixing air distribution system in the existing aircrafts' ventilation systems.

\section{Acknowledgements}

This project is supported and funded by Egyptian Airports Company and South Valley University. The authors would like to thank Dr. Tamer Elsayed, Helwan University, Egypt for providing the computing resources for our threedimensional numerical calculations. Moreover, the authors are sincerely grateful to Dr Imran Afgan, The University of Manchester, UK for his valuable discussions during writing this paper.

\section{REFERENCES}

[1] V. Bianco, O. Manca, S. Nardini and M. Roma, "Numerical investigation of transient thermal and fluidynamic fields in an executive aircraft cabin," $A p$ plied Thermal Engineering, vol. 29, no. 16, pp. 3418-3425, 2009. DOI: https://doi.org/10.1016/j.applthermaleng.2009.05.020

[2] S. C. Lee, C. S. Poon, X. D. Li and F. Luk, "Indoor air quality investigation on commercial aircraft," Indoor Air, vol. 9, no. 3, pp. 180-187, 1999. DOI: https://doi.org/10.1111/j.1600-0668.1999.t01-1-00004.x 
[3] M. B. Hocking, "Passenger aircraft cabin air quality: Trends, effects, societal costs, proposals," Chemosphere, vol. 41, no. 4, pp. 603-615, 2000.

DOI: https://doi.org/10.1016/S0045-6535(99)00537-8

[4] G. Rui and Z. Zhaowei, "Forecasting the air passenger volume in singapore: An evaluation of time-series models," International Journal of Technology and Engineering Studies, vol. 3, no. 3, pp. 117-123, 2017.

DOI: https://doi.org/10.20469/ijtes.3.40004-3

[5] T. Zhang and Q. Chen, "Comparison of different ventilation systems for commercial aircraft cabins," in Proceedings of Indoor Air, Beijing, China, 2005.

[6] T. Zhang and Q. Chen, "Novel air distribution systems for commercial aircraft cabins," Building and Environment, vol. 42, no. 4, pp. 1675-1684, 2007.

DOI: https://doi.org/10.1016/j.buildenv.2006.02.014

[7] Y. Sun, Y. Zhang, A. Wang, J. L. Topmiller and J. S. Bennet, "Experimental characterization of airflows in aircraft cabins, part I: Experimental system and measurement procedure," ASHRAE Transactions, vol. 111, no. 2, pp. 45-52, 2005.

[8] A. Wang, Quantifying air distribution, ventilation effectiveness and airborne pollutant transport in an aircraft cabin mock-up," Ph.D dissertation, University of Illinois, Urbana-Champaign, IL, 2006.

[9] Y. Zhang, Y. Sun, A. Wang, J. L. Topmiller, J. S. and Bennett, "Experimental characterization of airflows in aircraft cabins, part II: Results and research recommendations." ASHRAE Transactions, vol. 111, no. 2, pp. 53-59, 2005

[10] A. Wang, Y. Zhang, Y. Sun and X. Wang, "Experimental study of ventilation effectiveness and air velocity distribution in an aircraft cabin mockup," Building and Environment, vol. 43, no. 3, pp. 337-343, 2008.

DOI: https://doi.org/10.1016/j.buildenv.2006.02.024

[11] W. Yan, Y. Zhang, Y. Sun and D. Li, "Experimental and CFD study of unsteady airborne pollutant transport within an aircraft cabin mock-up," Building and Environment, vol. 44, no. 1, pp. 34-43, 2009.

DOI: https://doi.org/10.1016/j.buildenv.2008.01.010

[12] Z. Zhang, X. Chen, S. Mazumdar, T. Zhang and Q. Chen, "Experimental and numerical investigation of airflow and contaminant transport in an airliner cabin mockup," Building and Environment, vol. 44, no. 1, pp. 85-94, 2009.

DOI: https://doi.org/10.1016/j.buildenv.2008.01.012

[13] C. H. Lin, K. H. Dunn and R. H. Horstman, et al., "Numerical simulation of airflow and airborne pathogen trans- port in aircraft cabins-Part I: Numerical simulation of the flow field," ASHRAE Transactions, vol. 111, no. 1, pp. 755-763, 2005.

[14] M. S. Nugroho and M. Suryanegara, "Analysis of interference of unmanned aircraft system (UAS) and fixed service at frequency band $12.5-12.75 \mathrm{GHz}$ by considering the factor of rain attenuation," Journal of Advances in Technology and Engineering Studies, vol. 2, no. 5, pp. 164-169, 2016.

DOI: https://doi.org/10.20474/jater-2.5.4

[15] C. H. Lin, K. H. Dunn and R. H. Horstman, et al., "Numerical simulation of airflow and airborne pathogen transport in aircraft cabins-Part II: Numerical simulation of airborne pathogen transport," ASHRAE Transactions, vol. 111, no. 1, pp. 764-768, 2005.

[16] S. B. Poussou, S. Mazumdar, M. W. Plesniak, P. E. Sojka and Q. Chen, "Flow and contaminant transport in an airliner cabin induced by a moving body: Model experiments and CFD predictions," Atmospheric Environment, vol. 44, no. 24, pp. 2830-2839, 2010.

DOI: https://doi.org/10.1016/j.atmosenv.2010.04.053

[17] C. Wu and N. A. Ahmed, "A novel mode of air supply for aircraft cabin ventilation," Building and Environment, vol. 56, pp. 47-56, 2012.

DOI: https://doi.org/10.1016/j.buildenv.2012.02.025

[18] C. Wu and N. A. Ahmed, "Numerical study of transient aircraft cabin flow field with unsteady air supply," Journal of Aircraft, vol. 48, no. 6, pp. 1994-2001, 2011.

DOI: https://doi.org/10.2514/1.C031415

[19] V. Yakhot, S. A. Orszag, S. Thangam, T. B. Gatski and C. G. Speziale, "Development of turbulence models for shear flows by a double expansion technique," Physics of Fluids A: Fluid Dynamics, vol. 4, no. 7, pp. 1510-1520, 1992. DOI: https://doi.org/10.1063/1.858424

[20] S. M. Phyoe, Y. X. Lee and Z. W. Zhong "Determining the future demand: Studies for air traffic forecasting," International Journal of Technology and Engineering Studies, vol. 2, no. 3, pp. 83-86, 2016.

DOI: https://doi.org/10.20469/ijtes.2.40004-3

[21] E. H. Hunt and D. R. Space, "The airplane cabin environment," TSP, vol. 3, no. 2, pp. 1-12, 1994.

[22] Z. Zhang, W. Zhang, Z. J. Zhai and Q. Y. Chen, "Evaluation of various turbulence models in predicting airflow and turbulence in enclosed environments by CFD: Part 2-Comparison with experimental data from literature," Hvac\&R Research, vol. 13, no. 6, pp. 871-886, 2007. DOI: $10.1080 / 10789669.2007 .10391460$ 
[23] C. H. Lin, T. T. Wu, R. H. Horstman, P. A. Lebbin, M. H. Hosni, B. W. Jones and B. T. Beck, "Comparison of large eddy simulation predictions with particle image velocimetry data for the airflow in a generic cabin model," HVAC\&R Research, vol. 12, no. S3, pp. 935-951,
2006.DOI: $10.1080 / 10789669.2006 .10391218$

[24] T. Zhang, Q. Y. Chen and C. H. Lin, "Optimal sensor placement for airborne contaminant detection in an aircraft cabin," HVAC\&R Research, vol. 13, no. 5, pp. 683-696, 2007. DOI: $10.1080 / 10789669.2007 .10390980$

— This article does not have any appendix. - 